\title{
Voltammetric determination of theophylline at a Nafion/multi-wall carbon nanotubes composite film-modified glassy carbon electrode
}

\author{
SULING YANG ${ }^{1}$, RAN YANG $^{1}$, GANG LI ${ }^{3}$, JIANJUN LI ${ }^{1}$ and LINGBO QU ${ }^{1,2,3, *}$ \\ ${ }^{1}$ Department of Chemistry, Zhengzhou University, Zhengzhou 450001, P.R. China \\ ${ }^{2}$ Chemistry and Chemical Engineering School, Henan University of Technology, \\ Zhengzhou 450001, P.R. China \\ ${ }^{3}$ College of Chemistry and Chemical Engineering, Anyang Normal University, Anyang 455002, \\ P.R. China \\ e-mail: qulingbo@zzu.edu.cn
}

MS received 6 March 2010; revised 8 May 2010; accepted 14 June 2010

\begin{abstract}
A Nafion/multi-wall carbon nanotubes (MWNTs) composite film-modified electrode was fabricated and applied to the sensitive and convenient determination of theophylline (TP). Multi-wall carbon nanotubes (MWNTs) were easily dispersed homogeneously into $0.1 \%$ Nafion methanol solution by sonication. Appropriate amount of Nafion/MWNTs suspension was coated on a glassy carbon electrode. After evaporating methanol, a Nafion/MWNTs composite film-modified electrode was achieved. TP could effectively accumulate at Nafion/MWNTs composite film-modified electrode and cause a sensitive anodic peak at around $1180 \mathrm{mV}$ (vs SCE) in $0.01 \mathrm{~mol} / \mathrm{L} \mathrm{H}_{2} \mathrm{SO}_{4}$ medium $(\mathrm{pH} 1.8)$. In contrast with the bare glassy carbon electrode, Nafion film-modified electrode, Nafion/MWNTs film-modified electrode could remarkably increase the anodic peak current and decreased the overpotential of TP oxidation. Under the optimized conditions, the anodic peak current was proportional to TP concentration in the range of $8.0 \times 10^{-8}-6.0 \times 10^{-5} \mathrm{~mol} / \mathrm{L}$, with a detection limit of $2.0 \times 10^{-8} \mathrm{~mol} / \mathrm{L}$. This newly developed method was used to determine TP in drug samples with good percentage of recoveries.
\end{abstract}

Keywords. Theophylline; Nafion; multi-wall carbon nanotubes; voltammetry.

\section{Introduction}

Theophylline (1,3-dimethylxanthine) as a xanthine derivative has been commonly used as an additional treatment drug in the asthmatic acute phase in children and asthma and bronchospasm in adults. ${ }^{1-3}$ It is also used clinically as diuretic, cardiac stimulant and smooth muscle relaxant. However, appropriate dosing is indispensable because of the serious side adverse reactions in the presence of high concentrations of theophylline. ${ }^{4-6}$ Thus, more and more scientists have paid increasing attention to the techniques for the quantitative determination of theophylline. The chemical structure of theopylline is shown in figure 1 .

At present, many methods have been employed for measuring theophylline quantitatively, such as liquid chromatography, ${ }^{7,8} \mathrm{UV}$ spectrometry, ${ }^{9}$ chemiluminescent immunoassay, ${ }^{10}$ gas chromatography-

*For correspondence mass spectrometry (GC-MS) and gas chromatography-isotope dilution mass spectrometry (GCIDMS). ${ }^{11,12}$ Nevertheless, some of these methods, such as chromatography and mass spectrometry, are time-consuming, expensive, and need complicated preconcentration or multisolvent extraction as well as trained technicians. Instead, electrochemical methods are characterized by simplicity, high sensitivity, good stability, low-cost instrumentation and

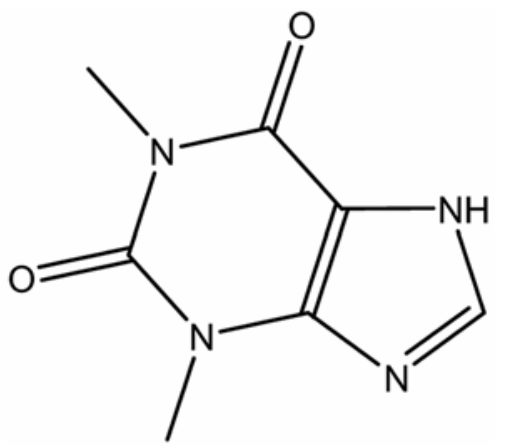

Figure 1. The chemical structure of theopylline. 
on-site monitoring. ${ }^{13}$ Thus, they are exploited for the determination of theophylline. In order to enhance the sensitivity and stability of the measurements, the electrodes modified with designable molecules have been used in electrochemical determination of theophylline, but electroanalysis of theophylline were seldom reported ${ }^{14-19}$ because of the oxidation of theophylline occurring at a very high positive potential and apt congregating on electrode surface. For instance, Zen et al. employed a Nafion/leadruthenium oxide pyrochlore chemically modified electrode for the voltammetric determination of TP in tea and drug formulation with a detection limit of $1.0 \times 10^{-7} \mathrm{~mol} / \mathrm{L} .{ }^{17}$ Ferapontova et al. developed the microbial theophylline oxidase electrode for the determination of $\mathrm{TP}$ with a detection limit of $0.02 \mathrm{mmol} / \mathrm{L},{ }^{18}$ but the stability of the biosensor was bad because of the degradation of enzyme activity. A boron-doped diamond electrode and a cobalt phthalocyanine $(\mathrm{CoPc})$ nanoparticles modified carbon paste electrode were also reported for TP assay with the detection limit was about $10^{-7} \mathrm{~mol} / \mathrm{L},{ }^{19,20}$ but the fabrication process of the above electrodes was complicated, and the rejuvenescence of the electrodes surface was troubled. Recently, a multiwall carbon nanotubes (MWNTs) modified glassy carbon electrode (GCE) was exploited for voltammetric determination of $\mathrm{TP}$ with a concentration range from $3.0 \times 10^{-7}$ to $1.0 \times 10^{-5} \mathrm{~mol} / \mathrm{L},{ }^{16}$ but it was not easy to homogenously disperse MWNTs in pure water.

In recent years, carbon nanotubes (CNTs) have received increasing attention to the preparation of modified electrodes due to their unique structures and extraordinary properties, such as huge surface area, strong stability and efficient catalytic activity which can promote charge transfer reaction. ${ }^{21-24} \mathrm{At}$ present, CNTs are widely used in electrochemical and electroanalytical filed.

In this paper, a convenient, economical and simple method was used to fabricate Nafion/MWNTs composite film-modified glassy carbon electrode. Nafion, as a perfluorinated sulfonate polymer, was always selected as the modifier and binder in many electrode fabrication procedures because of its good affinity towards many molecules and helping in getting good adhesion. ${ }^{25-27}$ The voltammetric behaviour of theophylline was evaluated at the modified electrode. A sensitive and well-defined anodic peak appeared. Compared with the bare glassy carbon electrode, the Nafion/MWNTs modified electrode could intensively enhance the anodic peak current and decrease the overpotential of TP oxidation. According to the oxidation peak current of theophylline sensitively responding to the theophylline concentration, the modified electrode was applied to the determination of theophylline in real drug samples with good percentage recoveries.

\section{Experimental}

\subsection{Apparatus}

RST3000 electrochemical system (Suzhou Risetech Instrument Co., Ltd. Suzhou, China) was employed for all the voltammetric measurements. A conventional three-electrode system was used, including a bare glassy carbon electrode (GCE) $(d=4 \mathrm{~mm})$ or Nafion/MWNTs film modified GCE as working electrode, a saturated calomel as reference electrode and a platinum wire as auxiliary electrode. All the $\mathrm{pH}$ values were measured with a PHS-3C precision pH meter (Leici Devices Factory of Shanghai, China), which was calibrated with standard buffer solution every day. The scanning electron microscopy (SEM) was performed with a Hitachi X-650 microscope.

\subsection{Reagents and solutions}

Theophylline was purchased from National Institute for the Control of Pharmaceutical and Biological Products (China) and used as received. The stock solution of theophylline $\left(2.0 \times 10^{-3} \mathrm{~mol} / \mathrm{L}\right)$ was prepared with doubly distilled water, and diluted with $0.01 \mathrm{~mol} / \mathrm{L} \mathrm{H}_{2} \mathrm{SO}_{4}(\mathrm{pH} 1.8)$ medium before use. The multi-wall carbon nanotubes (diameter: $10-20 \mathrm{~nm}$, length: $1-2 \mu \mathrm{m}$ purity $>95 \%$ ) were obtained from Shenzhen Nanotech Port Co., Ltd, China. Nafion (wt. 5\%) was purchased from Sigma. All the other chemicals used were analytical grade without further purification and prepared with double-distilled water. All solutions used in the measurements were not deoxygenated with nitrogen bubbling, and performed at room temperature.

\subsection{Procedure}

The bare GCE was pretreated carefully with $0.05 \mu \mathrm{m}$ alumina slurry on a polishing cloth, and then rinsed thoroughly with $1: 1 \mathrm{HNO}_{3}-\mathrm{H}_{2} \mathrm{O}(\mathrm{v} / \mathrm{v})$, pure ethanol and redistilled water in turn. $10 \mathrm{mg}$ untreated MWNTs was added into plentiful concen- 
trated nitric acid (wt. 68\%), and then sonicated for about $4 \mathrm{~h}$, and then washed with redistilled water several times until the $\mathrm{pH}$ of the solution reached to neutral ( $\mathrm{pH}$ 7). The carboxylic MWNTs were dried and stored until use. After $5.0 \mathrm{mg}$ carboxylic MWNTs was sonicated in $10.0 \mathrm{~mL} 0.1 \%(\mathrm{w} / \mathrm{w})$ Nafion methanol solution for about $30 \mathrm{~min}$, Nafion/MWNTs suspension would be achieved. The pretreated GCE was caoted with $10.0 \mu \mathrm{L}$ Nafion/ MWNTs suspension evenly. After methanol evaporated at room temperature, Nafion/MWNTs/GCE was obtained. For contrast, the Nafion/GCE was prepared in the same procedure without MWNTs.

The microscopic areas of the Nafion/MWNTs/ GCE and the bare GCE were obtained by cyclic voltammetry using $1.0 \mathrm{mmol} / \mathrm{L} \mathrm{K}_{3} \mathrm{Fe}(\mathrm{CN})_{6}$ as a redox probe containing $0.1 \mathrm{~mol} / \mathrm{L} \mathrm{KCl}$ at different scan rates. ${ }^{28,29}$ For a reversible process, the anodic peak current $i_{p}$ is linear to $v^{1 / 2}$ as follows:

$$
i_{p}=\left(2.69 \times 10^{5}\right) n^{3 / 2} A C_{0} D_{\mathrm{R}}{ }^{1 / 2} v^{1 / 2},
$$

where $i_{p}$ refers to the anodic peak current, $A$ the surface area of the electrode, $v$ the scan rate and $C_{0}$ the concentration of $\mathrm{K}_{3} \mathrm{Fe}(\mathrm{CN})_{6}$. For $1.0 \mathrm{mmol} / \mathrm{L}$ $\mathrm{K}_{3} \mathrm{Fe}(\mathrm{CN})_{6}$, the electron transfer $n=1$, the diffusion coefficient $D_{\mathrm{R}}=7.60 \times 10^{-6} \mathrm{~cm}^{2} / \mathrm{s}$. Thus, from the slope of the $i_{p}$ vs $v^{1 / 2}$ relation, the microscopic areas of the Nafion/MWNTs modified GCE was calculated to be $0.8668 \mathrm{~cm}^{2}$, which was about seven times greater than the bare GCE $\left(0.1256 \mathrm{~cm}^{2}\right)$.

Except as otherwise stated $0.01 \mathrm{~mol} / \mathrm{L} \mathrm{H}_{2} \mathrm{SO}_{4}(\mathrm{pH}$ $1.8)$ was used as supporting electrolyte for theophylline determination. A stock solution of $2.0 \times 10^{-3}$ $\mathrm{mol} / \mathrm{L}$ theophylline was firstly prepared, and then an aliquot was diluted to the appropriate concentration with $0.01 \mathrm{~mol} / \mathrm{L} \mathrm{H}_{2} \mathrm{SO}_{4}(\mathrm{pH} 1.8)$ before commencing the voltammetric scan. Voltammograms were obtained by scanning the potential from 500 to $1400 \mathrm{mV}$ (vs SCE). After each measurement, the three-electrode system was repeated successively in a blank solution for three times for the electrode to renew. The quantitative determination of theophylline was achieved by measuring the oxidation peak current after background subtraction using differential pulse voltammetry (DPV). Two tablets of theophylline sustained-release tablets were ground into powder. $0.1 \mathrm{~g}$ triturated powder was dissolved in $10 \mathrm{~mL}$ warm water and sonicated for half an hour, then filtrated. Some of the filtrate was diluted by a factor of $1 / 2000(\mathrm{v} / \mathrm{v})$, aminophylline injection by a factor of $1 / 12500(\mathrm{v} / \mathrm{v})$ with supporting electrolyte for the TP determination.

\section{Results and discussion}

\subsection{Characterization of Nafion/MWNTs/GCE}

The surface morphology of Nafion/MWNTs/GCE was illustrated by recording SEM image. As shown in figure 2, Nafion/MWNTs composite film was homogeneously coated on the electrode surface and displayed three-dimensional reticular formation, which revealed a much larger real surface area than

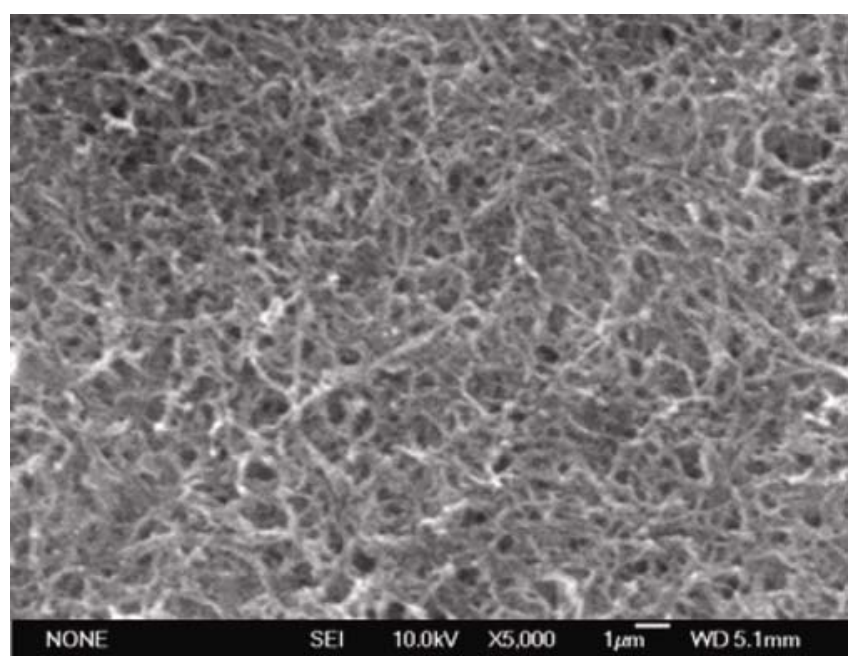

Figure 2. SEM image of Nafion/MWNTs composite film on glassy carbon electrode.

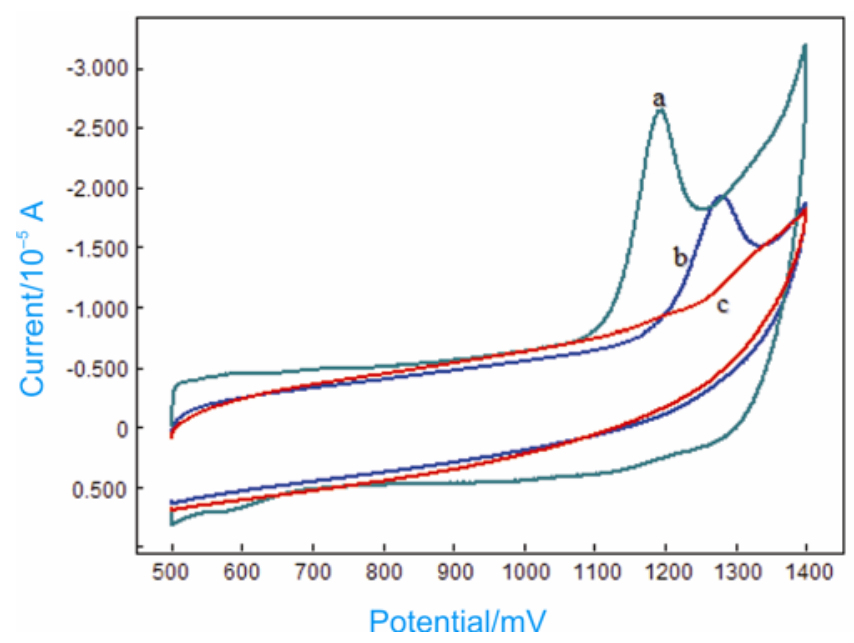

Figure 3. Cyclic voltammograms of the Nafion/ MWNTs modified GCE (a) Nafion modified GCE, (b) the bare GCE, (c) in $0.01 \mathrm{~mol} / \mathrm{L} \mathrm{H}_{2} \mathrm{SO}_{4}(\mathrm{pH} 1.8)$ medium containing $2.0 \times 10^{-5} \mathrm{~mol} / \mathrm{L}$ theophyline; scan rate $100 \mathrm{mV} / \mathrm{s}$. 
the apparent geometric area. The enhancement of surface area improved the capacitance at the modified electrode.

\subsection{Electrochemical response of TP at Nafion/MWNTs/GCE}

Figure 3 indicated the electrochemical behaviour of TP at Nafion/MWNTs/GCE (curve a), Nafion/GCE (curve b) and a bare GCE (curve c) in $0.01 \mathrm{~mol} / \mathrm{L}$ $\mathrm{H}_{2} \mathrm{SO}_{4}$ medium $(\mathrm{pH} 1.8)$ containing $2.0 \times 10^{-5} \mathrm{~mol} / \mathrm{L}$ TP. Under the same conditions, almost no anodic peak was observed at the bare GCE (curve c). When the bare GCE surface was coated with $0 \cdot 1 \%$ Nafion film, a well-shaped anodic peak appeared at about $1280 \mathrm{mV}$ (curve b). This phenomenon showed the fact that Nafion was a cation exchanger with high cation-exchange capacity and attracted TP from bulk solution to the electrode surface. Compared with Nafion/GCE, at Nafion/MWNTs/GCE, the peak current of TP observably increased and the anodic peak potential shifted negatively from $1280 \mathrm{mV}$ to $1180 \mathrm{mV}$ (curve a). The experimental results indicated that the Nafion/MWNTs/GCE could hold higher accumulation capability and notably improve the electrochemical sensitivity of TP. The cation exchange ability of Nafion and the excellent properties of MWNTs, such as its particular electronic structure, high electrical conductivity, topological

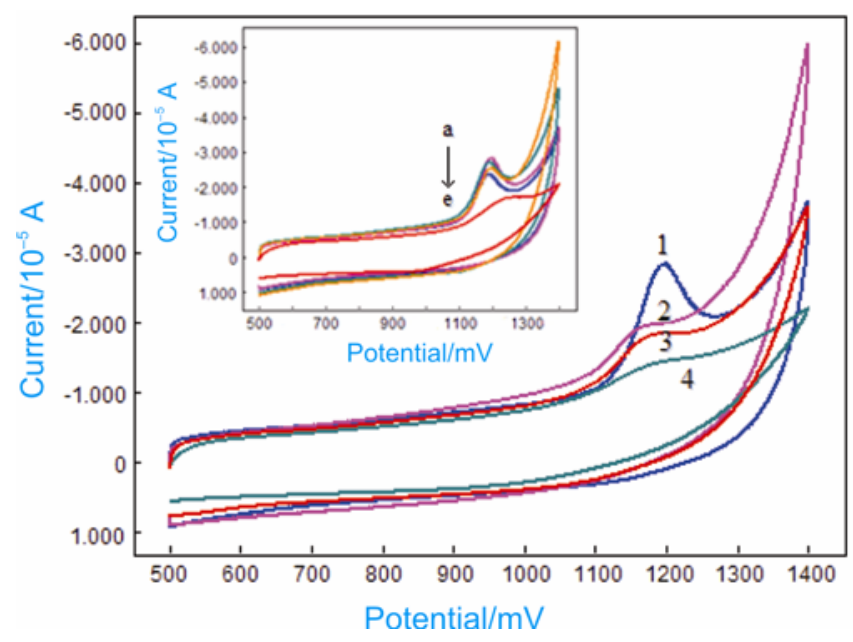

Figure 4. Cyclic voltammograms of the Nafion/ MWCNTs modified GCE in the presence of $2.0 \times$ $10^{-5} \mathrm{~mol} / \mathrm{L}$ TP in different supporting electrolytes $(1 \rightarrow 4): 0.01 \mathrm{~mol} / \mathrm{L} \mathrm{H}_{2} \mathrm{SO}_{4}, 0 \cdot 1 \mathrm{~mol} / \mathrm{L}$ phosphate buffer $(\mathrm{pH} 3 \cdot 0), 0 \cdot 1 \mathrm{~mol} / \mathrm{L}$ acetate buffer $(\mathrm{pH} 3 \cdot 0), 0 \cdot 1 \mathrm{~mol} / \mathrm{L}$ borate buffer $\left(\mathrm{pH} \mathrm{5.5)}\right.$; insert $(\mathrm{a} \rightarrow \mathrm{e}): 0.01 \mathrm{~mol} / \mathrm{L} \mathrm{H}_{2} \mathrm{SO}_{4}$, $\mathrm{HNO}_{3}, \mathrm{HCl}, \mathrm{H}_{3} \mathrm{PO}_{4}, \mathrm{CH}_{3} \mathrm{COOH}$; scan rate $100 \mathrm{mV} / \mathrm{s}$. defects present on their surfaces and its nano-meter dimensions induced analyte to fully contact with the bare GCE, and then promoted the electrocatalytic oxidation process of TP. ${ }^{30-32}$

\subsection{Influence of supporting electrolyte and $\mathrm{pH}$ on the peak current and peak potential}

To optimize the determination condition of TP, the influence of supporting electrolyte, such as $0.1 \mathrm{~mol} / \mathrm{L}$ phosphate buffer ( $\mathrm{pH} 3 \cdot 0-7 \cdot 0)$, acetate buffer $(\mathrm{pH}$ 3.0-7.0), borate buffer ( $\mathrm{pH} 5.5-8 \cdot 0$ ), $0.04 \mathrm{~mol} / \mathrm{L} \mathrm{B-R}$ buffer $(\mathrm{pH} 2 \cdot 0-8 \cdot 0)$, as well as $0.01 \mathrm{~mol} / \mathrm{L}$ various acids $\left(\mathrm{HCl}, \mathrm{HNO}_{3}, \mathrm{H}_{2} \mathrm{SO}_{4}, \mathrm{H}_{3} \mathrm{PO}_{4}\right.$ and $\left.\mathrm{CH}_{3} \mathrm{COOH}\right)$ were investigated (figure 4 ). The results showed that only in lower $\mathrm{pH}$ buffer system TP could exhibit higher peak current. $\mathrm{H}_{2} \mathrm{SO}_{4} \quad(0.01 \mathrm{~mol} / \mathrm{L})$ was selected as the supporting electrolyte.

The influence of solution $\mathrm{pH}$ on the response of TP was examined at a scan rate of $100 \mathrm{mV} / \mathrm{s}$ (figure 5). With the increasing $\mathrm{pH}$ from 0.7 to $4 \cdot 2$, negative shift of anodic peak potential was observed, indicating that hydrogen ions were concerned with the electrode reaction. The peak potential showed a linear relationship with $\mathrm{pH}$ between $\mathrm{pH} 0.7$ and $\mathrm{pH}$ $4 \cdot 2$ as follows:

$$
\begin{aligned}
E_{\mathrm{p}}= & 1.2688-0.0306 \mathrm{pH} \\
& \left(E_{\mathrm{p}} \text { in } \mathrm{V}, \text { correlation coefficient }=0.9987\right) .
\end{aligned}
$$

The slope of $30.6 \mathrm{mV} / \mathrm{pH}$ (figure 5 inset) was similar to the value of $28 \mathrm{mV} / \mathrm{pH}$ reported, ${ }^{14}$ which revealed

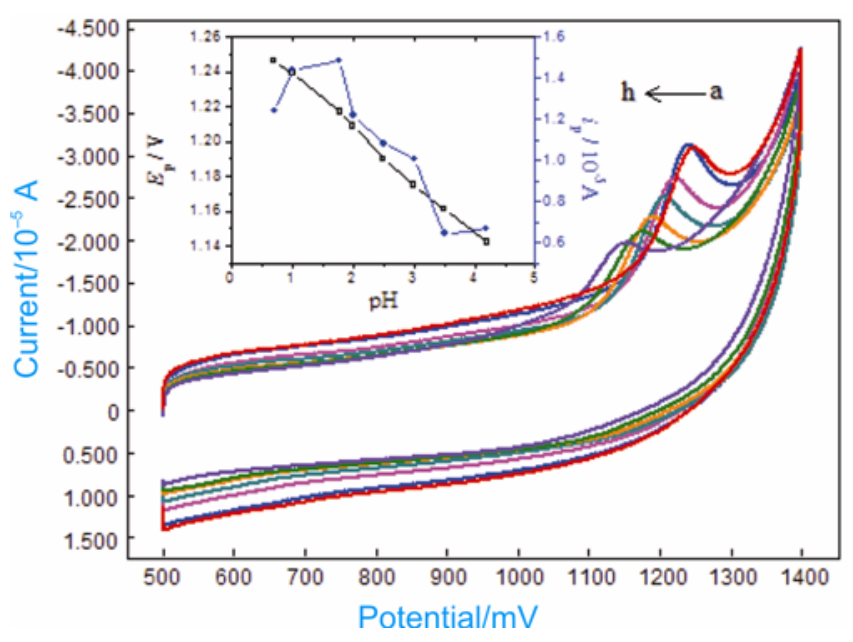

Figure 5. Cyclic voltammograms of the Nafion/ MWNTs/GCE in the presence of $2.0 \times 10^{-5} \mathrm{~mol} / \mathrm{L} \mathrm{TP}$ with different $\mathrm{pH}$ of $0.01 \mathrm{~mol} / \mathrm{L} \mathrm{H}_{2} \mathrm{SO}_{4}$ mediums $(\mathrm{a} \rightarrow \mathrm{g})$ : $0 \cdot 7,1 \cdot 0,1 \cdot 8,2 \cdot 0,2 \cdot 5,3 \cdot 0,4 \cdot 2$; inset: $E_{\mathrm{p}}, i_{\mathrm{p}}$ vs $\mathrm{pH}$ plot; other conditions as in figure 3. 
that the number of electron transfer was two times more than that of hydrogen ions participating in the electrode reaction.

As seen from figure 5, $\mathrm{pH} 1.8$ was selected as the optimized $\mathrm{pH}$ for determination of TP due to the lower peak potential and highest peak current $\left(i_{p}\right)$. Minimum peak current in $\mathrm{pH} 4 \cdot 2$ demonstrated that probable rate step was controlled with one preequilibrium proton dependent reaction. As the dissociation constant $\mathrm{pKa}$ of TP was $8 \cdot 77,,^{33}$ it presented as $\mathrm{TPH}^{+}$in $\mathrm{pH} 1.8 \mathrm{H}_{2} \mathrm{SO}_{4}$ solution in fact. $\mathrm{TPH}^{+}$ could be more effectively adsorbed and accumulated on the electrode surface due to the ion exchange and electrostatic attraction with Nafion as well as MWNTs.

\subsection{Effect of scan rate on the peak current and peak potential}

The effect of scan rate $(v)$ on the peak current and peak potential at Nafion/MWNTs/GCE in $0.01 \mathrm{~mol} / \mathrm{L}$ $\mathrm{H}_{2} \mathrm{SO}_{4}$ medium (pH 1.8) was investigated by cyclic voltammetry in the presence of $2.0 \times 10^{-5} \mathrm{~mol} / \mathrm{L} \mathrm{TP}$. As shown in figure 6 , the peak current $i_{p}$ versus $v$ gave a straight line until $v$ was up to $300 \mathrm{mV} / \mathrm{s}$. The linear regression equation was: $i_{\mathrm{p}}=0.0154 v+$ $0.3697\left(i_{\mathrm{p}}\right.$ in $10^{-5} \mathrm{~A}, v$ in $\mathrm{mV} / \mathrm{s}$, correlation coefficient $=0.9971)$, which indicated that an adsorptiondriven oxidation process carried out at Nafion/ MWNTs/GCE.

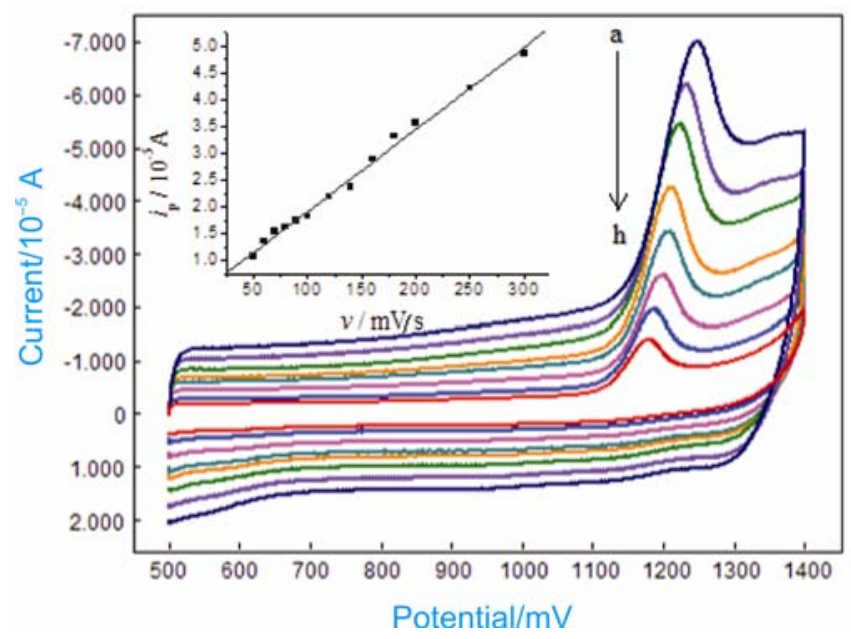

Figure 6. Dependence of peak current of the Nafion/ MWCNTs/GCE on different scan rates in the presence of $2.0 \times 10^{-5} \mathrm{~mol} / \mathrm{L}$ TP $(\mathrm{a} \rightarrow \mathrm{h}): 300,250,200,160,140$, $100,60,40 \mathrm{mV} / \mathrm{s}$; insert is the $i_{\mathrm{p}} \mathrm{vs} v$ plot; other conditions as in figure 3.
In order to clarify the electrode reaction nature of $\mathrm{TP}$, the repetitious cyclic voltammograms of TP in $0.01 \mathrm{~mol} / \mathrm{L} \quad \mathrm{H}_{2} \mathrm{SO}_{4}$ supporting electrolyte were recorded. Figure 7 showed that the peak current in the second cyclic scan decreased remarkably compared with that of the first cyclic scan. After the second cyclic scan, the peak current decreased negligibly. This phenomenon might be another evidence for the adsorption-driven oxidation process of TP occurring at Nafion/MWNTs/GCE.

The peak potential shifted to the positive direction with the increasing scan rate. The variation of peak potential with $v$ from 40 to $300 \mathrm{mV} / \mathrm{s}$ followed the regression equation: $E_{\mathrm{p}}=1.0931+0.0229 \ln v\left(E_{\mathrm{p}}\right.$ in $\mathrm{V}, v$ in $\mathrm{mV} / \mathrm{s}$, correlation coefficient $=0.9960$ ).

Based on the theory of Laviron, ${ }^{34}$ for an irreversible anodic reaction, the linear relationship of $E_{\mathrm{p}}-v$ is given by the following equation:

$$
E_{\mathrm{p}}=E^{\circ}-\frac{R T}{a n F} \ln \frac{R T K s}{a n F}+\frac{R T}{a n F} \ln v
$$

where $E^{0}$ is formal standard potential; $\alpha$ is the charge transfer coefficient; $n$ is the number of the electrons transferred; $F$ is the Faraday constant $(96500 \mathrm{C} / \mathrm{mol})$ and $k_{\mathrm{s}}$ is the standard heterogeneous reaction rate constant. $R$ and $T$ have their usual meaning. From the slope of $E_{\mathrm{p}}$ vs $\ln v, \alpha n=1.12$ was obtained, when assuming $n=2,{ }^{16}$ the value of $\alpha$ was 0.56 . The value of $E^{\circ}=1.17 \mathrm{~V}$ was got from the intercept of linear relationship $E_{\mathrm{p}}$ against $v$ on the ordinate by extrapolating the line to $v=0$, and from

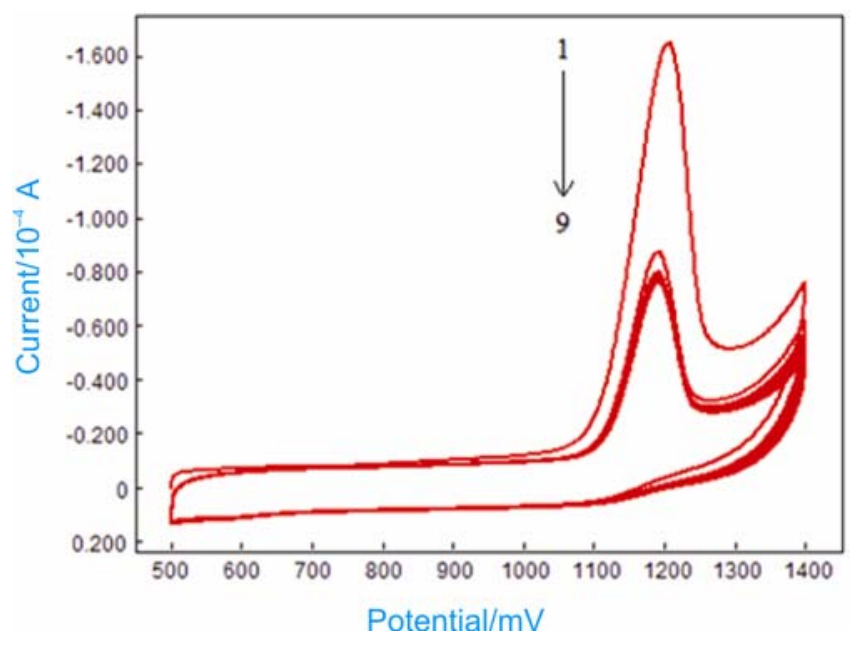

Figure 7. Nine times of repetitious cyclic voltammograms of Nafion/MWNT/GCE in the presence of $2 \cdot 0 \times 10^{-4} \mathrm{~mol} / \mathrm{L} \mathrm{TP}$; other conditions in figure 3 . 
the intercept of the straight line of $E_{\mathrm{p}}$ versus $\ln v$, $k_{\mathrm{s}}=6.70 \mathrm{~s}^{-1}$ was calculated. However, the scan rate of $100 \mathrm{mV} / \mathrm{s}$ was selected as the optimum value in the determination of TP because of the higher current, lower peak potential and smaller background current.

\subsection{Edetermination of maximum surface coverage $\Gamma_{\max }$}

The value of peak current of TP is closely related to the maximum surface coverage $\left(\Gamma_{\max }\right)$, which is adsorbed on the working electrode surface. From the electric charges consumed for electro-oxidation of the surface-accumulated reactant, $\Gamma_{\max }$ can be determined according to the following equation ${ }^{35}: \Gamma_{\max }=$ $Q / n F A$, where $\Gamma_{\max }$ is the maximum surface-attached material concentration $\left(\mathrm{mol} / \mathrm{cm}^{2}\right), Q$ is the maximum electric charge measured under the adsorptive voltammetry $(A \mathrm{~d} V)$ peak, and $A$ is the electrode geometric area $\left(\mathrm{cm}^{2}\right)$. The maximum surface coverage of TP on Nafion/MWNTs/GCE was calculated to be $7.20 \times 10^{-10} \mathrm{~mol} / \mathrm{cm}^{2}$. On the assumption that the surface adsorption was a monolayer, the occupied area of one adsorbed TP molecule was $0.23 \mathrm{~nm}^{2}$.

\subsection{Calibration curve}

In order to validate the practicality of this method for TP quantitative analysis, the variation of peak current with different concentration TP was studied using differential pulse voltammetry (DPV) due to its high sensitivity and excellent resolution (figure 8). Under the optimum instrumental conditions (pulse amplitude: $40 \mathrm{mV}$, pulse increment: $8 \mathrm{mV}$; pulse width: $45 \mathrm{~ms}$; pulse period: $120 \mathrm{~ms}$ ), the peak current was linear to the TP concentration in the range of $8.0 \times 10^{-8}-6.0 \times 10^{-5} \mathrm{~mol} / \mathrm{L}$. The regression equation was: $i_{\mathrm{p}}=0.0703 C+0.2825\left(i_{\mathrm{p}}\right.$ in $10^{-5} \mathrm{~A}$, $C$ in $\mu \mathrm{mol} / \mathrm{L}$, correlation coefficient $=0.9989$ ). The detection limit of TP were estimated to be $2 \cdot 0 \times 10^{-}$ ${ }^{8} \mathrm{~mol} / \mathrm{L}$. Except Liu's report, ${ }^{14}$ the detection limit of TP was lower than that of the reported literatures. ${ }^{15-20}$ But the preparation process of the Nafion/MWNTs/ GCE was much more convenient, economical, simpler and rapid than that of Liu's report. ${ }^{14}$

Regeneration and reproducibility are the two vital characteristics for the modified electrode, which should be investigated for analytical determination. The same Nafion/MWNTs/GCE was used for five times successive measurement of $2.0 \times 10^{-5} \mathrm{~mol} / \mathrm{L}$
TP. After each measurement, the surface of the Nafion/MWNTs/GCE was regenerated by successive scan cycle between 500 and $1400 \mathrm{mV}$ in $0.01 \mathrm{~mol} / \mathrm{L} \quad \mathrm{H}_{2} \mathrm{SO}_{4}$ medium solutions for three cycles. The relative standard deviation (RSD) of the peak current was $2 \cdot 4 \%(n=5)$, which revealed the good regeneration and reproducibility. Moreover, under the same preparing conditions, for five Nafion/MWNTs/GCEs, the RSD of the peak current was $6.3 \%$, declaring the good reproducibility. After Nafion/MWNTs/GCE was stored in phosphate solution $\left(\mathrm{pH} \mathrm{7.0)}\right.$ ) for thirty days at $4^{\circ} \mathrm{C}$, the decrease of the peak current is just $15.0 \%$, indicating good durability of the sensor.

\subsection{Interference studies}

The influence of potential coexistent interference compounds should be studied for the possible ana-

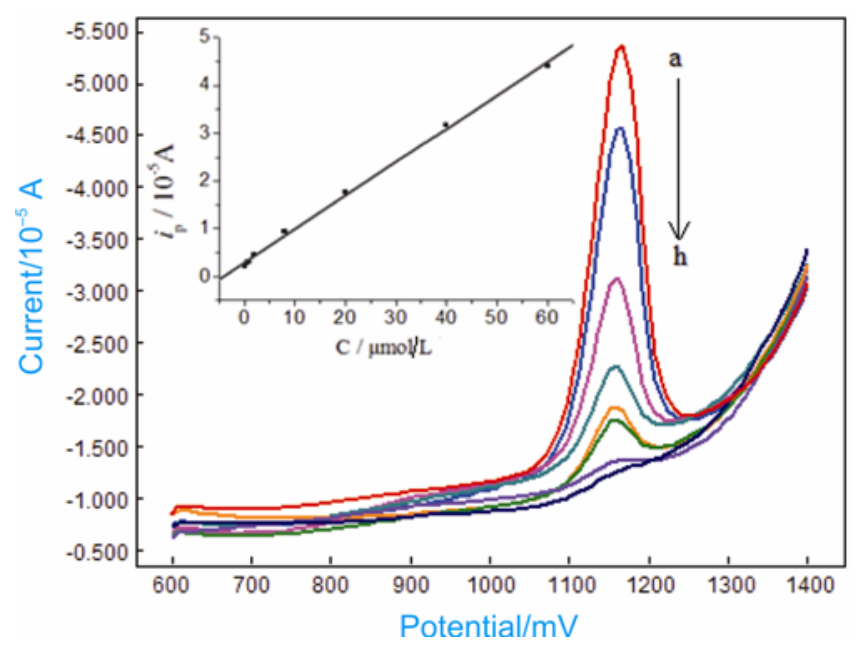

Figure 8. Differential pulse voltammograms of Nafion/ MWNTs/GCE in different concentrations of TP $(\mathrm{a} \rightarrow \mathrm{h})$ : $6.0 \times 10^{-5}, 4.0 \times 10^{-5}, 2.0 \times 10^{-5}, 8.0 \times 10^{-6}, 6.0 \times 10^{-6}$, $4.0 \times 10^{-6}, 6.0 \times 10^{-7}, 1.0 \times 10^{-8} \mathrm{~mol} / \mathrm{L}$; inset is the $i_{\mathrm{p}}$ vs $C$ plot. Instrument parameters; pulse amplitude, $40 \mathrm{mV}$, pulse increment, $8 \mathrm{mV}$; pulse width, $45 \mathrm{~ms}$; pulse period, $120 \mathrm{~ms}$.

Table 1. Tolerance limits $\left(C_{\text {species }} / C_{\mathrm{TP}}\right)$ of the analytical signal of TP $\left(2.0 \times 10^{-5} \mathrm{~mol} / \mathrm{L}\right)$ in the presence of various interfering substances $(n=5)$.

\begin{tabular}{lc}
\hline Species & $\begin{array}{c}\text { Tolerance limits } \\
\left(C_{\text {species }} / C_{\mathrm{TP}}\right)\end{array}$ \\
\hline Glucose, sucrose, citric acid, amino acid & 200 \\
$\mathrm{Cu}^{2+}, \mathrm{Zn}^{2+}, \mathrm{Fe}^{3+}, \mathrm{Mg}^{2+}$ & 200 \\
$\mathrm{~K}^{+}, \mathrm{Na}^{+}, \mathrm{CO}_{3}^{2-}, \mathrm{Cl}^{-}, \mathrm{PO}_{4}^{3-}, \mathrm{NO}_{3}^{-}$ & 500 \\
Hypoxanthine & 10 \\
Ascorbic acid & 30 \\
\hline
\end{tabular}


Table 2. Determination results of TP in aminophylline injection and theophylline sustained-release tablets by DPV $(n=5)$.

\begin{tabular}{lcccccc}
\hline Sample & 1 & 2 & 3 & 4 & Average & RSD/\% \\
\hline Aminophylline injection (g/ampoule) & 0.2076 & 0.1862 & 0.1988 & 0.1978 & $0 \cdot 1976$ & $3 \cdot 84$ \\
Theophylline sustained-release tablets (g/tablet) & 0.0935 & 0.0902 & 0.0915 & 0.0935 & 0.0921 & 1.52 \\
\hline
\end{tabular}

Table 3. Determination of TP in aminophylline injection and theophylline sustained-release tablets diluents using the standard added method and Nafion/MWNTs/GCE.

\begin{tabular}{lcccc}
\hline Sample & Original $/ 10^{-5} \mathrm{~mol} / \mathrm{L}$ & Added $/ 10^{-5} \mathrm{~mol} / \mathrm{L}$ & Found $/ 10^{-5} \mathrm{~mol} / \mathrm{L}$ & Recovery $/ \%$ \\
\hline Aminophylline injection & 2.98 & $2 \cdot 00$ & 4.90 & $96 \cdot 00$ \\
& & $0 \cdot 80$ & $3 \cdot 80$ & $102 \cdot 50$ \\
& & $0 \cdot 08$ & 3.07 & $112 \cdot 50$ \\
Theophylline sustained-release tablets & 1.02 & $2 \cdot 00$ & $2 \cdot 94$ & 96.00 \\
& & $0 \cdot 80$ & $1 \cdot 86$ & 105.00 \\
& & 0.08 & 1.11 & 112.50 \\
\hline
\end{tabular}

lytical application of the proposed method. A fixed amount of $2.0 \times 10^{-5} \mathrm{~mol} / \mathrm{L}$ TP spiked with various foreign species was evaluated under the same experimental conditions. As shown in table 1, the results were clearly proved the reasonable selectivity of the proposed method according to the relative error $< \pm 10 \%$ for the anodic currents of TP.

\subsection{Analysis of pharmaceutical samples}

For the purpose of practical applicability, theophylline sustained-release tablet and aminophylline injection were purchased. In order to fit into the linear range of the method, theophylline sustainedrelease tablet and aminophylline injection employed for operation were accurately diluted with the supporting electrolyte, respectively. Nafion/MWNTs/ GCE was used for the determination of theophylline in real samples. The experimental results were shown in table 2. As seen from table 2, the content of TP in theophylline sustained-release tablet was calculated to be $0.0921 \mathrm{~g}$ per tablet (the declared content was $0.1 \mathrm{~g}$ per tablet); the content of TP in aminophylline injection was calculated to be $0.1976 \mathrm{~g}$ per ampoule (the declared content was $0.2 \mathrm{~g}$ per ampoule). The determined contents of TP were in agreement with the declared contents of TP in real samples, which demonstrated that the proposed methods could be efficiently used for the determination of TP. To evaluate the accuracy of the method, standard addition method was used by spiking different concentration of TP in real sample solutions. Good percentage recoveries were obtained from both samples (see table 3).

\section{Conclusions}

The feasibility of the Nafion/MWNTs/GCE for the determination of TP was demonstrated in this study. The Nafion/MWNTs/GCE not only remarkably enhanced the oxidation peak current of TP, but also decreased the oxidation overpotential, which showed high performance towards the electrocatalytic oxidation of TP. The peak current of DPV were linear to the concentration of TP in the range from $8.0 \times 10^{-8}$ to $6.0 \times 10^{-5} \mathrm{~mol} / \mathrm{L}$ with a detection limit of $2 \cdot 0 \times 10^{-8} \mathrm{~mol} / \mathrm{L}$. The proposed method displayed excellent characteristics, such as simplicity, lowcost, high sensitivity, good selectivity, rapid analysis procedures and a large determination range. The modified electrode was applied to the detection of TP in real drug samples with good percentage recoveries.

\section{Acknowledgements}

We would like to acknowledge the financial support from the National Natural Science Foundation of China (No. 20472076) and the Natural Science Foundation of Henan Province, China (No. 0512001400).

\section{References}

1. Igarashi and S Iwakawa 2009 Biol. Pharm. Bull. 32 307

2. Kanehara M, Yokoyama A, Tomoda Y, Shiota N, Iwamoto H, Ishikawa N and Taooka Y 2008 Pulm. Pharmacol. Ther. 21874 
3. Kawai Mand Kato M 2000 Find. Exp. Clin. Pharmacol. 2309

4. Blake K and Kamada A K 1996 Textbook of therapeutics: drug and disease management (Williams and Wilkins: Baltimore) 6651

5. Weinberger M, Hendeles L and Engl N $1996 \mathrm{~J}$. Med. 3341380

6. Minton N A and Henry J A 1996 Human Exp. Toxicol. 15471

7. Srdjenovic B, Djordjevic-Milic V and Grujic 2008 J. Chromatographic. Science 46144

8. Huang X L and Xu M Y 2005 Se Pu. 23296

9. Culzoni M J, De Zan M A, Robles J C, Mantovani V E and Goicoechea H C 2005 J. Pharmaceut. Biomed. 391068

10. Zhou M X, Guan C Y, Chen G, Xie X Y and Wu S H 2005 J. Zhejiang. Univ. Sci. B6 1148

11. Arinobu T, Hattori H,. Kumazawa T, Lee X P, Mizutani Y, Katase T, Kojima S, Omori T, Kaneko R, Ishii A and Seno H 2009 Forensic. Toxicol. 271

12. Kress M, Meissner D, Kaiser P, Hanke R and Wood W G 2002 Clin. Lab. 48541

13. Sadik O A, Land W H and Wang J 2003 Electroanalysis. 151149

14. Liu L Q, Xiao F, Li J W, Wu W B, Zhao F Q and Zeng B Z 2008 Electroanalysis 201194

15. Miroslav S, Andrea P, Stanislav M and Jozef S 2000 Anal. Biochem. 285225

16. Yuan H Z, Zhang Z L and Pang D W 2005 J. Electroanal. Chem. $\mathbf{5 8 1} 303$

17. Zen J M, Yu T Y and Shih Y 1999 Talanta 50635
18. Elena E F, Stepan S and Lo G 2007 Biosens. Bioelectron. 222508

19. Yang G J, Wang K, Xu J J and Chen H Y 2004 Anal. Lett. 37629

20. Spataru N, Sarada B V, Tryk D A and Fujishima A 2002 Electroanalysis $\mathbf{1 4} 721$

21. Rochefort A, Avouris P, Lesage F and Salahub D R 1999 Phys. Rev. B60 13824

22. Ajayan P M 1999 Chem. Rev. 991787

23. Wu K B, Fei J J and Hu S S 2003 Anal. Biochem. 318 100

24. Hu C G and Feng B 2005 Int. J. Mod. Phys. B19 603

25. Erdogdu G 2003 J. Anal. Chem. 58569

26. Cheng H L and Sun I W 2001 Electroanalysis 13 1544

27. Wang Z, Zhang H, Zhou S and Dong W 2001 Talanta 531133

28. Xu Q and Wang S F 2005 Microchim. Acta 15147

29. Behzad R and Zohreh M Z S 2008 Sensor. Actuat, B-Chem. 134292

30. Britto P J, Santhanam K S V, Rubio A, Alonso J A and Ajayan P M 1999 Adv. Mater. 11154

31. Musameh M, Lawrence N S and Wang J 2005 Electrochem. Commun. 714

32. Banks C E and Compton R G 2006 Analyst. 13115

33. Riahi S, Mousavi M F, Bathaie $S Z$ and Shamsipur M 2005 Anal. Chim. Acta 548192

34. Laviron E 1979 J. Electroanal. Chem. 10119

35. Bard A J and Faulkner L R 1980 Electrochemical methods fundamentals and applications (New York: Wiley) 522 